\title{
Care leavers in early adulthood: how do they fare in England, Finland and Germany?
}

Claire Cameron ${ }^{1}$, Katie Hollingworth ${ }^{1}$, Ingrid Schoon ${ }^{1}$, Eric van Santen ${ }^{2}$, Wolfgang Schröer ${ }^{3}$, Tiina Ristikari ${ }^{4}$, Tarja Heino ${ }^{5}$, Elina Pekkarinen ${ }^{6}$

${ }^{1}$ Department of Social Science, UCL Institute of Education, University College London, 27-28 Woburn Square, London, WC1H 0AA, England. Email: c.cameron@ucl.ac.uk (Corresponding author)

${ }^{2}$ Deutsches Jugendinstitut e. V. (German Youth Institute (DII)), Abteilung Jugend und Jugendhilfe (Department Youth and Youth Welfare), Nockherstrasse 2, 81541 Munich, Germany

${ }^{3}$ Institut für Sozial- und Organisationspädagogik, Universitätsplatz 1, D-31141 Hildesheim, Germany ${ }^{4}$ National Institute for Health and Welfare, Finland, Department of children, youth and families, Mannerheimintie 166, 00271 Helsinki, Finland

${ }^{5}$ National Institute for Health and Welfare, Finland, Department of children, youth and families, Aapistie 190101 Oulu, Finland

${ }^{6}$ Finnish Youth Research Network, Asemapäällikönkatu 1, 00520 Helsinki, Finland. 


\title{
Care leavers in early adulthood: how do they fare in England, Finland and Germany?
}

\author{
Abstract \\ In this paper we examine the longer term outcomes of young people who experienced out of home \\ care $(\mathrm{OHC})$ as children, in Britain, Germany and Finland, countries characterised by different welfare \\ regimes. While there is some evidence on immediate transitions after leaving care (up to age 21), \\ there is less evidence on experiences around age 30, a phase of early adulthood. Drawing on existing \\ longitudinal data for general population samples we focus on outcomes related to education, \\ employment, family, health and receipt of welfare benefits for those who were ever in care and \\ those who were not. We find evidence for continuing disadvantage regarding education and \\ employment for those who were in care as children, but also indications of subjective wellbeing and \\ commitment to family life - possibly a reflection of 'normality' and efforts to 'fit in' as parents. \\ Surprisingly, despite variations in welfare system and differences in the scope and quality of \\ available data, trends were similar in each of the countries, suggesting that none provide adequately \\ for the needs of care experienced young adults. The findings point towards the need for a revised \\ conceptualisation of the notion of 'independence' which has to take into account the manifold and \\ changing relationships between individuals and the state. Instead of a 'cliff edge' approach there \\ should be support for a more gradual shift from 'dependence' to 'independence' enabling those with \\ care experience to develop their full potential. In interpreting the findings, limitations of the \\ available data has to be acknowledged, pointing to the need for generating harmonised and \\ longitudinal data on vulnerable subpopulations to enable effective monitoring of needs and \\ provision.
}

Keywords

Care experienced young adults, out of home care, longitudinal studies, youth transitions, independence 


\section{Introduction}

First descriptive insights into the longer term fortunes of children who experienced out of home care $(\mathrm{OHC})$ in three European countries shows that comparable data that tracks outcomes related to education, work, family life, health and use of welfare benefits at or around age 30 is lacking. Population level data is either not available or does not capture the experience of ageing out of care accurately. Scandinavian countries are rare exceptions. In this paper we attempt to track, using population level data, the longer-term experiences of those who were in state care as children, compared to those who were not, at a point in time when young adults are expected to have established their careers and settled into family life. We describe the background to the study, reflecting on the conceptualisation of 'independence' and its relevance in capturing the realities of those we describe as 'care leavers'. We then discuss the different country contexts and policies related to leaving care and describe available longitudinal data sources. Findings are reported on transition outcomes where possible before we discuss the evidence, highlighting needs for harmonised data and future research.

\subsection{Background to the study}

Over a million children in Europe live in out of home care ${ }^{1}$ with foster carers, or in residential care institutions of various kinds (Eurochild, 2010) usually due to parental neglect, abuse or abandonment. Legislative protection usually ceases at age 18 and little administrative monitoring continues beyond this age. On average the time spent in OHC e.g. in England is approaching three years (McGrath-Lone, 2018). We thus use the term 'care leaver' to indicate that most of these children have to readjust to live outside the care of the state, especially after they reach the age of majority (usually age 18). When young people leave the protective care of the state, what do we know about their long term fortunes? Internationally agreed guidelines assume that young people will be financially independent and self-reliant once prepared by their care settings and employers should be encouraged to recruit care leavers (UN, 2010).

For young people overall, youth transitions are now considerably extended, with lengthening educational participation, delayed entry into employment and prolonged dependence on parents (Billari \& Liefbroer, 2010; Buchmann \& Kriesi, 2011; Settersten \& Ray, 2010). More young people continue to live with their parents or return to the parental home, especially young males. For example, within the EU in 2013 , over $70 \%$ of young men aged $20-24$ and $60 \%$ of young women lived

\footnotetext{
${ }^{1}$ The terms used to refer to children living under the auspices of the state differ cross-nationally. We use the following terms: out of home care, public care, state care and being looked after in care to refer to the same legal status.
} 
with their parents (Eurostat, 2015). There are, however, considerable variations by country. For example, in Finland, only $28 \%$ of young people ( $41 \%$ males and $15 \%$ females) aged $20-24$ were living with their parents, compared to $56 \%$ in the UK (67\% males and $45 \%$ females) and $78 \%$ in Germany (86\% males and 70\% females). Moreover, following the 2008 recession employment opportunities for young people have dramatically declined (Bell \& Blanchflower, 2011) and increasing numbers of young people struggle to find employment and are increasingly facing the prospect of temporary and precarious employment (Schoon \& Bynner, 2017). In terms of both age and level and type of support, the position is especially challenging for young people who have grown up in public care.

Leaving care has been marked as a much more accelerated transition than leaving home (Stein, 2006). Expectations that care leavers were 'independent' of the support of the state by the age of 18 are out of step with both their peer group and the everyday realities of their lives. Leaving care early is a barrier to the acquisition of resilience, skills and qualifications required to thrive as young adults. Leaving care at a defined and young age deprives young people of the opportunity to deal with major changes sequentially, and imposes on them simultaneous stress in relation to housing tenancies, employment, education, friendship and other relationships, managing finances and so on (Hollingworth \& Jackson 2016; Stein, 2006; Kääriälä \& Hiilamo, 2017). There is no opportunity to try out, reframe and reflect on adversities (Stein, 2006; Singer \& Berzin, 2015). These 'accelerated and compressed' transitions apply to care leavers across Western Europe (Stein \& Munro, 2008), while in Eastern European countries the pattern is 'extended and abrupt', characterised by young people leaving care at an older age but still ill-prepared for the demands of independent living when the support previously provided is suddenly withdrawn (Stein, 2013).

Positioning young people who are leaving care as 'independent' or 'not dependent' (Propp et al., 2003) at a much earlier age than their contemporaries who have not been in care as children puts them at risk of high unemployment (Harris Rome \& Raskin 2017), low post secondary educational participation and attainment (Courtney \& Hook 2016;), and combining multiple responsibilities, or perceiving it as inappropriate, inhibits asking for help (Hiles et al., 2013; Cameron, 2007; Pryce et al., 2017). They are also likely to have continuing poor mental health (Geigar \& Beltan, 2017). Particular educational risks are associated with some ethnic identities (O'Brien et al., 2010).

1.2 Care leaving within a welfare state: transition regimes and concepts of independence A narrow conceptualisation of 'independence' as 'not being dependent' on welfare services or 'selfsufficiency (Propp et al., 2003) fails to take account of the many relationships between individuals and the welfare state in young adulthood. Instead of seeing independent life as a process of 'leaving 
behind' public care where the transition benchmark is living without support from social or pedagogic services, independence is better conceptualised as a gradual process involving a changing and different relation to support within the welfare state. This process can be characterised by multiple qualities of interdependencies in care leavers' personal life and is structured by transition regimes (Walther, 2015). Early evidence suggests that care leavers benefit from extended post placement support (Okpych et al., 2018; Munro et al., 2012).

State-personal life interdependencies might be, for example, autonomously claiming welfare or disability benefits, using family support services and accessing financial support for students, being a citizen and using free health care, tax relief, not to need help and having ongoing personal relationships with carers and so on. At the core of this transformation from a 'cliff edge' approach, where a young person shifts from 'dependence' to 'independence' at a particular point in the life course, is the way 'independence' as a young person or an adult is framed by the transition regime. Is independence (in terms of not being dependent on the welfare state) a desirable state of being? Possibly it is not reflective of the reality of people's lives.

Different youth transition regimes (Walther, 2015) utilise different images of young people and their relations within welfare states. In universal transition regimes, such as Finland, young people are seen as citizens and the pathway to adulthood is regulated mainly by social rights, an extended welfare system combined with an inclusive schooling system. In liberal transition regimes, such as Britain, or most English speaking countries, there is a focus on the economic, political and social autonomy of young people which aims to have an open and flexible structure of the pathways to adulthood with easy access to employability. At the same time employment is often combined with high risk and low access to welfare. A third type is conservative transition regimes, for example, Germany, which are characterized by an institutionalized pathway to adulthood which are more selective and standardised with a focus mostly on (pre-) vocational training. Emerging adults themselves may put more emphasis on personal and financial self-reliance than acquisition of life course roles to define adulthood (Singer \& Berzin, 2015).

Overall, transition is not just about casting off childhood dependency, albeit in various ways, but also about varying images of how young people engage in education, employment, family life and welfare states. These images influence the well-being in the independent life of care leavers in a fundamental manner. Our analysis of data from Britain, Finland and Germany will focus on the question of whether and what empirical data we have available to discuss this specific constellation of the relation between independent life in young adulthood of care leavers and welfare states. 
Figure 1 shows the possible dimensions of care leaving. Young people who leave care must negotiate social or care or health services (labelled 'social service' below), vocational and job training systems that support employment in different labour markets ('work'), as well as bringing a legacy of past participation and, often, continued participation in schooling and college ('education'). These are the care and educational structures most relevant to young people as they leave care. In a second step, it would be helpful to analyse family policy related to tax systems as well. Only with this perspective, can we show how support of young adults, who live in a range of environments, is indirectly carried out by the state.

Figure 1. Dimensions of Care Leaving

We analyse available data, in Finland, England and Germany, focusing on the early adult (aged 28 31) lives of 'care leavers'. Each country represents a different relationship to the role of the state in offering social protection, with a focus on the transition into independent adulthood (Walther, 2009). We compare the educational attainment, employment status, health and life satisfaction, family status, and whether claiming welfare benefits, of those who have ever been in care with those how have never been in care. Where possible we examine the impact of early or late entry to care on adult outcomes. We are particularly concerned with whether there is any evidence that young people who have been in care 'recover' from early disadvantage in later life (Mendes et al., 2014). To what extent do their employment patterns, family status, health status and interaction with the system of welfare benefits at age 28-31, reflect those of the never in care population or are there distinctive pathways associated with having been in care? This is intentionally a descriptive paper. As we set out in more detail below, there are significant differences in the datasets available across the three countries which inhibit comparison.

\section{Country contexts for out of home and leaving care}

\subsection{Out of Home Care}

Table 1 sets out the some features of the in care population in the three countries studied. Between .6 and $1.4 \%$ of children under the age of 18 are in care at any one time. Proportionately fewer young people come into care in Germany (2.5\% likelihood over period 0-18 years) than in the other 
countries but the length of stay is estimated to be seven years, compared to an average of 32 months in England when placements are administratively linked ${ }^{2}$ (McGrath Lone 2018).

Table 1 here.

Reasons for entry to care vary but are concerned with abuse and neglect, family dysfunction and acute stress (England, 85\% of total); and difficult family circumstances interlinked with behavioural and psychiatric symptoms, substance abuse and criminal behaviour, and school related difficulties, often connected to learning difficulties, attention deficit and hyperactivity disorders in Finland (Manninen, 2013). In Germany, in 2015 reasons for entry to out of home care were: child not cared for (20.6\%); insufficient support/stimulation/care in the family (11.7\%); danger to the child's welfare (11.7\%); limited parenting skills (16.4\%); child burdened by parental problems (9.2\%); by familial conflicts (7.8\%); social behaviour (8.7\%); developmental difficulties (8.1\%); and school/vocational problems (5.8\%).

The higher proportion of children in care in Finland is probably accounted for by two factors: i) inclusion of young people with a criminal record; ii) use of in care placements as a family support measure, known as 'placed in care'. Alternatively, having an 'in care decision' signals that a child cannot live at home and needs foster or residential care. In 2017, $71 \%$ of children in care were placed on voluntary basis, and $68 \%$ children had an 'in care decision' (Child Welfare Finland, 2017).

\subsection{Leaving Care}

At age 18, there is provision in law in all three countries for some continuing support. In England ${ }^{3}$ public authorities are required to maintain contact with and support young people who leave their care up to age 21 and 25 in some circumstances. In 2016, there were about 26,000 care leavers aged 19-21. Each year, about 8,000 young people are discharged from care on their 18th birthday. Very few leave care after the age of 18 ; most access care leaver support instead. One option is to 'stay put' if in a settled foster care placement; in 2016 only 1230 young people aged 19 or 20 were doing so (DfE, 2016).

\footnotetext{
2 Figures for England exclude those children who are convicted of crimes. In July 2017 there were 924 children under the age of 18 who had been convicted of a crime and were accommodated in secure children's homes (Youth Justice Board 2017)

${ }^{3}$ Britain has devolved administrations for children in care. In Scotland and Wales the proportion of children in local authority care is approximately one percent and .8 percent respectively. Since administrative data sets do not capture longer term outcomes in this paper we use data for Britain (BCS70) and England (LSYPE). Policy positions are diverging over time but were broadly similar at the time of data collection.
} 
In Finland, young people with a history in out-of-home care have a right to 'after care' support, which the municipality is required to arrange until the age of 21 . After care is voluntary, and should offer both financial and social support such as help with housing, education, hobbies, and living expenses, as well as psycho-social support with dealing with the challenges of independent everyday life. However, there are major differences in the quality, content, and intensity of the services and support of after care in different parts of the country. In 2016, 6,694 formerly placed individuals received after care support and 1,774 continued living in the foster home or institution as after care (Child welfare Finland, 2017).

In Germany, about two thirds of placements end before age 18; there is provision in law for assistance up to the age of 21 and even 27 in certain justified cases. The law also states that care leavers should be advised and supported to the extent necessary after completion of the assistance in the process of becoming independent. There are no statistics but it appears few young people access this support. Of those who left care in $2015,29.3 \%(16,204)$ did so after age 17.

\section{Data sources}

We draw on birth cohort studies, administrative data and panel surveys which compare care leavers with the general population who have never been in care. We sit country data alongside each other; comparability is limited due to the lack of harmonised data and differing definitions and practices across the three welfare regimes. Table 2 sets out the data sources, sample size and response rates.

Table 2 about here

\subsection{British data}

The British Cohort Study (BCS70) is the most comprehensive data set recording those who were in care as children, whose participants were aged 30 in 2000. This is now somewhat dated, so we situate some findings in the more contemporary Longitudinal Study of Young People in England (LSYPE), but whose participants are not yet 30 . This additional data shows similar trends to the BCS70. The BCS70 is a study of over 17,000 people born in England, Scotland and Wales in a single week of 1970. To date there have been 10 study 'sweeps' collecting information about cohort members at birth, age 5, 10, 16, 26, 30, 34, 38, 42 and 46 years. Data is collected on health, education, employment, housing, family and relationships, and welfare benefits. For descriptions of outcome variables see Elliott and Shepherd (2006).

In this analysis we focus on data collected in 1975, 1980, 1986 and in 2000 to map care experienced young people's outcomes at age 30. In 2000 there were 11,261 participating cohort members. BCS70 
at ages 5,10 , and 16 provides information on cohort members who were 'ever in care'. This produced, at age 5, 263 cohort members (1.4\% of cohort); at age 10, 312 (1.7\% of cohort), and at age 16,123 cohort members ( $1.3 \%$ of cohort). At age 30 a retrospective question asked if cohort members had ever been in care before age 17 and there were 177 (1.7\% of cohort). The prospective data yields a total of 698 cohort members for whom care placements were reported. Combining the data with those who reported to ever have been in care retrospectively at age 30 , there is a total of 875 cohort members for which we have a record (reported by parents or carers or by self-report) to have ever been placed in care. Linking all records over time, taking into account overlap between reports, we identified 616 cohort members (3.8\% of cohort) with a record of having ever been placed in out of home care before age 17. Linking the data with education, employment and family related outcomes, we have data for about 350 cohort members (numbers vary by outcome). Reporting 'ever' in care is a self-report of all episodes of local authority care, irrespective of duration. The dataset does not allow for more a nuanced assessment of the impact of care experience by duration.

LSYPE follows the lives of around 16,000 young people born in 1989-90. The study began in 2004, when the cohort members were aged 13-14, and has collected information about their education and employment, economic circumstances, family life, physical and emotional health and wellbeing (see Department for Education (2010) for descriptors of outcome variables). LSYPE holds records on 314 people who had ever been in care, identified at age 14/15. Again, it is not possible to assess the duration of care experience. Anonymised use of both BCS70 and LSYPE is freely available subject to conditions.

\subsection{Finnish data}

The 1987 Finnish Birth Cohort (FBC) study includes administrative records on 59,476 children born in Finland in 1987. It includes all live births and stillbirths of infants registered in the Medical Birth Register (MBR) (Paananen \& Gissler 2011; Ristikari et al., 2016). The 1987 FBC study consists of data regarding the use of health and social services, benefits, education and employment from both children and their parents. For the purposes of the current study we used information from the Register of Child Welfare (THL, National institute for Health and Welfare, Finland) to identify all children born in the year 1987, who, before their 18th birthday, had ever been placed in out of home care $(\mathrm{N}=1900)$. We differentiated between those 'placed' in care for family support, and those with an 'in care' decision, but the differences in outcomes between the two groups were not large so findings combine both groups. Much larger differences were found between those whose first 
entry was before the age of 13 and those with first entry after the age of 13. We also analysed the outcomes by gender, and found that males fare on average significantly worse than females.

We linked data from the register of child placements with data on employment, pensions and benefits from the Finnish Centre for Pension (ETK), data about the highest education received and deaths from Statistics Finland, use of psychiatric outpatient care and diagnosis from the hospital discharge register (THL), income support from register on social assistance (THL), psychotropics, disability and family benefits from the Social Insurance Institution's registers, and marriages from the Population Register Center. All linkages were done by using parents' and children's personal identity codes, which is available in most Finnish registers. Finnish national registers are of high quality and appropriate for research purposes Gissler \& Haukka (2004). Details of variables are available from Paananen \& Gissler (2011) and Ristikari et al., (2016). The study obtained ethics approval of the National Institute for Health and Welfare (Ethical committee \$28/2009), and permissions to use the register data was obtained from all register keeping organizations.

\subsection{German data}

Results from Germany are based on data from the Socio-Economic Panel (SOEP, Version 32). Comprehensive information about the data collection, design, participants, variables, and assessment procedures is reported in Wagner, Frick\& Schupp (2007) and Frick (2010). Since 1984, the SOEP has been providing the scientific community with longitudinal data (annual interviews) on a wide range of topics such as labour participation, income development, housing situation, changes in the household, satisfaction with different living areas and their social attitudes. From 2001 onwards, the survey included a question about the place of growing up to age 16 for all those participating in a second or subsequent panel wave. The data includes an approximation of the number of years spent in out of home care, but contains no information on the number of placements. The sample for the current study comprised 6,689 adults aged 20 to 40 years (born $1961-1995)(M=28.4$ years, $S D=6.9$ years $)$, whose data reported on outcome variables and lived in either residential care or foster care for at least one year $(n=148,2.2 \%$ of the sample) or were never in care placements that lasted longer than one year $(n=6,541)$.

\subsection{Attrition}

Attrition varies by data source. In BCS70, the response rate for data collected at age 30 in 2000 was $60 \%$. For care leavers the response rate was $40 \%$, and we do not know whether there are any particular characteristics associated with non-participants (Mustafa \&Wiggins 2014). In LSYPE, response rates were $74 \%$ at the first wave and $85-95 \%$ for all subsequent waves. Attrition rates in 
SOEP (Germany) differ by subsamples and years after first interview. They range between $22 \%$ and $45 \%$ after five years and between $38 \%$ and $57 \%$ after ten years (Kroh et al., 2015). There are only moderate differences in the risk of survey related attrition between groups (age, occupation, income, and education) (ibid.). As an administrative data set, there is no attrition in the Finnish 1987 FBC. These differences are likely to effect between country comparisons.

In summary, we examine records on approximately 2700 young adults who were in care as children. However, participating countries' data is derived from sources that have different study designs and criteria for entry, which may result in different populations being compared. In Britain, we have a cohort study born in 1970, and the entry criteria were 'ever in care' reported by participants at ages 5, 10, 16 and 30, supplemented with a cohort born in 1990 in England. In Finland, the data is from administrative records on a cohort born in 1987. The Finnish data allows for a nuanced categorization based on age, gender and type of placement, and we highlight differences in outcomes based on these categorizations. In Germany, the data is from waves of a panel study and defines 'ever in care' as placements exceeding 12 months in duration. For all variables, we examine the situation at 28-31 years. This approximates early adulthood when youth related transitions including higher education, and becoming a first time parent, are usually completed and 'independence' is likely to have been achieved for those who have never been in care.

\section{Findings}

In this section we examine care leavers transitions and status aged 28 - 31 in Britain, Finland and Germany. We consider: i) educational attainment; ii) employment and main activity; iii) family and social relationships; iv) health; and v) welfare benefits. For each we compare those who were ever in care with never in care, and sit these alongside results across countries. In some cases we can examine differences by earlier and later entry to care.

\subsection{Educational attainment}

The level of education was measured with the 9-level CASMIN classification (Comparative Analysis of Social Mobility in Industrial Nations). Table 1 shows the results from the three datasets. It is notable that in all countries those who have ever been in out of home care before age 17 are much more likely to have no qualifications and much less likely to have a higher level qualification than their contemporaries who have not been in care. The lower level of Finnish attainment of upper tertiary education may be due to ongoing participation at age 28 . Analyses by gender show males are at particular risk of having no qualifications (54.3 vs 37.2\%). Results in England suggest a higher level of tertiary education than official statistics on care leavers at age 19 (DfE, 2016) suggest, so possibly 
there is some 'catch up' over time. However, BCS70 data relate to 2000, before major policy reforms to promote higher education participation came into effect. At that time it was estimated that just one percent went to university (Jackson \& Sachdev 2001). LSYPE data shows that in 2010, at age $19 / 20,24 \%$ of care experienced young people attended university and about $10 \%$ participated in further education and training, including apprenticeships (results available on request). A more indepth analysis of education trajectories among care experienced young people in England is needed.

In Germany, around two thirds of both those who were in care and those who were not have CASMIN levels equivalent to secondary education. It is likely this relates at least in part to the attractiveness of the German apprenticeship training (Autorengruppe Bildungsberichterstattung, 2016, p. 102). Generally, both in Finland and Germany care leavers show similar levels of secondary level qualifications as non-care leavers, while in England care leavers show similar levels of lower tertiary qualifications as non-care leavers.

Table 1. CASMIN data for England, Finland and Germany, aged 28 - 31

Table 2 compares educational attainment at age 28-30 for those who enter care early in England and Finland. 'Early' means before age 10 in the British data and before 13 in Finland, which may mask population differences. Early entry was associated with CASMIN levels 1c - 3a (55\%) in England and CASMIN 1a-2c (91.2\%) in Finland. In Britain there is no difference between early experience of care and ever being in care regarding upper tertiary qualifications (both 19.2\%) but some increase for secondary and lower tertiary qualifications, suggesting that later entry into care might bring with it some disadvantages regarding completion of secondary and lower tertiary education - but not higher education.

Table 2. Highest CASMIN level by age 30, by age of entry, Britain and Finland.

Those who enter care after age 13 in Finland show a clear educational disadvantage at age 28; 95.5\% have a CASMIN level below 3 . This may indicate a problem of guidance during the secondary education phase: young people in care are rarely advised to pursue tertiary level education (Jackson \& Cameron 2014). It could also indicate high selectivity regarding entry into the academic track, preventing Finnish care leavers from fully developing their potential. Also, among the Finnish 1987 FBC approximately half of the children were placed as teenagers (Kestilä et al, 2012), and the main reason for teenage placements is related to schooling coupled with other behavioral problems 
(Heino et al, 2016). There is no equivalent later entry data in Britain. However, Sebba et al. (2015) found that, at age 16, in England, those who entered care at $10-15$ years, scored less well in external examinations than those who entered care at an earlier age, and accrued just over half the grades of those who had not been in care at all.

\subsection{Employment and training}

Table 3 shows the main activity of care experienced young people and the comparison group (those never in care) when aged 28 - 31. Differences in size of the shares are particularly evident with regard to full-time employment and unemployment. In all three countries, care leavers are over represented in economically inactive categories (unemployment, looking after home/family/other).

Table 3. Main activity of adults aged 28-31 who were 'ever in care' and 'never in care'.

Care experienced young people in England fare reasonably well in terms of labour market participation. About 66 percent of care leavers are employed by age 30 compared to 82 percent of those who had never been in care. In Finland the percentage point gap between care experienced and others was 30.7, and much larger than in England (16.3 percentage points). More females were in employment ( $44.5 \%$ vs $40.6 \%$ males) and a higher proportion of those entering care earlier (46.9\% of those first entering care before age 13 vs $37.8 \%$ of those entering after age 13). By contrast, in Germany, there was a rather small gap (6.6 percentage points) between ever in care and others, though the overall level of employment in early adulthood is lower. This is due to a rather high percentage of the sample still in, or re-entering, education, those in a voluntary social (or 'gap') year, and a lower participation of women in the labour market, as indicated by rates of economic inactivity (which in the German sample includes looking after the family).

When we examine unemployment, and combine this with the economically inactive category of looking after home and family, the three countries have a similar percentage gap between those ever in care and never in care (13.8ppt in Finland; 15.6 in Britain and 16 in Germany).

Supplementary data from LSYPE shows similar trends, with an over-representation of unemployment among young people who were in care as children ( $17.9 \%$ vs $6.12 \%$ at age 20$)$. This excludes those who were 'inactive', such as those looking after children, or otherwise at home. This would suggest an increased risk of precarious employment experiences among care leavers, pointing to a cycle of disadvantage - but also to a generally increased risk of precarious employment transition in the aftermath of the recession (Schoon \& Lyons-Amos 2016, 2017). 
Overall, country comparisons show similar trends, of continuing difficulties for those ever in care matching the never in care group in terms of educational and employment related attainment at around age 30, especially in Finland, and clear over-representation of the ever in care group among those unemployed, and in Britain, among those looking after home and/or family.

\subsection{Family Status}

By around age 30, differences between those who had been in care as children and those who had not were less pronounced in terms of family and personal relationships than in relation to education and employment. Table 4 shows that there was between one and eight percentage points difference between the ever in care and never in care groups across the three countries in having a settled partner.

Table 4. Family status, ever in care, never in care, England, Finland, Germany

Adults aged 28-31 who had been in care as children were more likely to have children than those who had not been in care. In Britain we find a higher rate of teenage parenthood among care leavers than among others (although this data is now somewhat old). Similarly in Finland, $18.7 \%$ of those ever placed had given birth before age 20 (vs. 3.6\% not placed) (Kestilä et al., 2012). Accelerated parenthood transitions among care leavers may be a way to establish 'normality' and/or emotional meaning into one's life or rectify poor relationships in their past by having 'someone to love' (Haydon 2003; Knight et al., 2006), although also associated with social deprivation (Mezey et al., 2017).

\subsection{Health status}

The data available regarding health status across countries is uneven. Some is recorded administratively, and some by self-report. Some items are only available in one country. Seen together, the variables build a picture. Table 5 combines health and life satisfaction (self-reported) with indicators of health difficulties, some self-report and some administratively defined. Selfreports of both health satisfaction and life satisfaction are quite positive, in both England and Germany (not available in Finland), although differences between the ever in care and never in care groups persist (10 - 14 percentage points).

Table 5. Health status, ever in care, never in care, England, Finland, Germany 
The ever in care group show markedly higher rates of depression (Britain and Finland), and elevated indicators of mental ill-health such as psychiatric diagnosis, psychotropic medicine use and early mortality with particularly large differences for those who first enter the care system later (e.g., $56.2 \%$ pre 13 years first time entrants in Finland have a psychiatric diagnosis vs $76.2 \%$ post 13 first time entrants). In the case of Finnish administrative data, it may be that the high figures reflect a system that is working well to support people who need health care rather than leave them alone to navigate highly complex service landscapes.

\subsection{Disability and welfare benefits}

A further aspect of 'independence' is disability status and the extent to which care leavers continue to access welfare benefits as adults and/or are homeless. There is no data to report from Germany so in Table 6 we examine the situation in England and Finland. The information on the selected indicators is however not harmonised, relying on self-reports of disability in Britain and official medical records in Finland. Perhaps surprisingly, the ever in care group in England are less likely than others to report a disability, while administrative data in Finland shows that a much higher proportion of those claiming a disability pension at age 28 were in care as children. Disability pensions in Finland are mainly based on mental health problems. However, a disability pension brings income, which merely declaring a disability does not. In Britain, self-reported receipt of various disability benefits and allowances shows that just over ten percent of those with care experience versus $4.4 \%$ of others received any disability benefits at age 30 . Likewise those seeking welfare benefits in relation to joblessness are more likely to have ever been in care and just $35 \%$ of the ever in care group had not claimed any welfare benefits. In Finland, a high proportion of the cohort received income support at some time before age 28 ( 87 percent of the ever in care and 39 percent of the never in care group). This indicates that the system is working well in supporting young people during a period of economic austerity, especially those who were ever in care, for whom public authorities retain a responsibility.

Table 6. Welfare benefit status, ever in care, never in care, England and Finland

Finally, there is an established association between care leavers and homelessness (Quilgars et al., 2008) which is borne out in this data. In England, there was a three times elevated risk of ever being homeless among the ever in care group (22.5\% vs $6.5 \%)$. In Finland, administrative data shows a very high incidence of study respondents being without an address before age 25 , but whether this 
reflects real homelessness or bureaucratic requirements require further investigation. It may be a consequence of forgetting to complete registering papers when moving.

\section{Discussion and Conclusion}

We set out to compare, using the best available data, the longer term outcomes of those who had experienced $\mathrm{OHC}$ with those who had not, in three countries that each represented a different type of youth transition regime. The first finding is that each of our three countries has markedly different data sources to address this question. Available sources are from administrative, birth cohort and panel data, with different timings, so that data for those aged 30 in 2000 in Britain is set alongside the age 28 group in 2015 in Finland. In Germany data from across the years 2001-2015 was harnessed. This clearly leads to imprecise comparisons; data is not harmonised; it was not collected with a particular focus on those leaving care at age 18 after a specific duration (apart from Finland); and nor can the data take account of changing policy contexts. The extent to which we can compare outcomes across countries is limited.

Second, while we anticipated differences by youth transition regimes the trend was rather similar in each country. When we compared those ever in care with the never in care group, there was a continuing legacy of adversity in terms of educational qualifications, and a comparatively high risk of being unemployed. The gap narrows in relation to employment in Germany and to some extent Britain by age 30 but remains high in Finland, perhaps reflecting the longer term educational participation profile in Finland. Notably, in Britain there appear to be relatively good prospects for care leavers to complete tertiary education (compared to care leavers in Germany and Finland), possibly reflecting the flexibility of the British education system and support for able students. The gap between the care experienced and others is narrower in relation to family formation: more of the ever in care group than other young people have their own children, particularly as young parents. The data on health and life satisfaction shows that positive self-evaluation endures for both groups but this is underlain with some stark differences in mental health difficulties.

These findings mirror those of other studies that draw attention to continuing adversity for those who were in care as children (Kääriälä \& Hiilamo, 2017; Pecora et al., 2006) but also points to indicators of wellbeing such as establishing committed relationships and a positive evaluation of one's life, perhaps a search for 'normality' and 'fitting in' as parents.

Third, it seems likely that none of the three transition regimes examined have systems that enable care experienced young people to thrive at a comparable level to their peers later in life - not even 
the Finnish welfare state, where we found very low levels of educational attainment beyond secondary level.

In fact, what the findings show is that a disproportionate number of care experienced young adults shift from one welfare arena to another. As we suggested, rather than 'independence' of the welfare state, we see interdependencies in terms of engagement with education, job support, health and disability services.

We might consider that the whole care and education structure - the transition process - as evolving qualities of social interdependencies and the idea of 'independence' at age 18, for many care leavers, needs to be reconceptualised. The ways in which interdependencies interact may have an impact on the success (or otherwise) of care leavers' transitions. Different transition regimes, characterised by varying welfare state provisions and expectations of individuals and families, may produce different relationships between 'independence' and 'interdependence'. Care leaving research might ask how the different qualities of interdependencies - in the area of education, employment, housing, health care and so on within a welfare state have an impact on the wellbeing in the personal life of care leavers? What kind of independency do these interdependencies enable? New questions arise, such as how to support an extended period of education among care leavers to enable them to compete with others in a labour market that increasingly demands graduate qualifications. Why, or whose interests are served by, conceptualising the care leaving process as explicitly linked to living without support from public services? How can a new concept of transforming dependency on social structures with a 'care obligation' make visible the ways in which we might better support care leavers through their twenties? For example, how and where do after care services guide care leavers in regards to education and work? What special dispensation for delay in acquiring educational qualifications is available? What measures are in place in universities and other educational establishments to address mental health or other difficulties of integration for care leavers? What does the delay in starting work and persistent unemployment mean for access to pensions and/or health services in later life? Does being a parent have the same protective qualities for care leavers as for non-care leavers?

The limitations of this study mostly concern the quality and comprehensiveness of the available data. Cross-national comparisons are problematic, especially when the orientation to the welfare state fundamentally differs (Hantrais, 2009; Gilbert et al., 2011). As pointed out, the data sources varied in type and the implications that can be drawn from the data, which may be somewhat out of date or gathered for a different purpose, must be cautiously interpreted. There are potential country 
differences in the way the care experience is defined and conceptualised, leading to different characterisation of the in-care population. In country comparisons were possible between those ever in care and never in care but the status 'ever' in care does not accurately reflect the length of time in care during childhood. Nor were we able to identify a more precisely defined comparison group - those who shared demographic characteristics but had not been in care. This would be a clear area for further study. Moreover, as in most longitudinal follow-up studies, the most disadvantaged, in particular males, are most likely to drop out (Mostafa \& Wiggins, 2014). Findings regarding longer-term outcomes, especially evidence from Britain and Germany, might thus be biased by sample attrition and potentially underestimate the magnitude of disadvantage. The Finnish data, on the other hand, includes all citizens, including those who may be likely to drop out in other study designs. The composition of the sample might explain the high rate of psychiatric diagnosis and psychotropic medicine use - and low levels of education in Finland.

Despite all the difficulties in cross-national comparison, this study provides clear evidence that in all three countries the care and associated welfare systems fail to sufficiently reorient young people's lives so that they may be 'getting some prospects' (Petrie et al., 2006) and thriving in young adulthood in comparable ways to those who never experienced care. The data consistently shows disadvantages associated with having been in care, that persist up to the age of around 30 in all three countries. It could be argued that it is unreasonable to expect a period in public care to compensate for all the problems that most children bring with them. However, an important contributory factor to negative long-term outcomes is the inadequate provision for continued support in early adulthood for which most other young people can look to their families (and that is something that could be remedied).

By working with what data is available we have established much common ground between these three European states in the outcome patterns for care leavers and opened up some new questions for research to address. In the case of Finland, for example, administrative data offers much potential, but there is no strategy in place to use it to support service development for care leavers. In England, cohort studies offer a rare opportunity to compare with the general population but low numbers of care leavers mean differentiation within the sample and accounting for the intensity of the care experience is impossible. In Germany, so much is not known about the wellbeing and pathways of care leavers, despite the comparatively large child in care population, that there is a clear case for more and better data derived from a new study.

Acknowledgements 
We are grateful to Professor Emeritus Sonia Jackson for her review of the paper, and to the UCL Global Engagement Fund and the National Institute for Health and Welfare, Finland, Academy of Finland grant 288960 and Academy of Finland funded PSYCOHORTS consortium for supporting the international collaboration.

References

Autorengruppe Bildungsbericht (2016). Bildung in Deutschland 2016. Ein Indikatiorengestüzter Bericht mit einer Analyse zu Bildung und Migration. Bielefeld: W. Bertelsmann Verlag

Bell, D. N., \& Blanchflower, D. G. (2011). Young people and the Great Recession. Oxford Review of Economic Policy, 27(2), 241-267. doi:10.1093/oxrep/grr011

Buchmann, M. C., \& Kriesi, I. (2011). Transition to Adulthood in Europe. Annual Review of Sociology, 37,481-503.

Billari, F. C., \& Liefbroer, A. C. (2010). Towards a new pattern of transition to adulthood? Advances in Life Course Research, 15(2-3), 59-75. doi:10.1016/j.alcr.2010.10.003

Cameron, C. (2007). Education and self-reliance among care leavers, Adoption and Fostering 31(1), 39-49.

Child Welfare Finland (2016) Statistics report 20/2016; 1798-0887, THL. Available from http://urn.fi/URN:NBN:fi-fe2016122031615

Courtney, M. \& Hook, J. (2017). The potential educational benefits of extending foster care to young adults: Findings from a natural experiment. Children and Youth Services Review, 72, 124-132

Department for Education (2016). Children looked after in England including adoption: 2015 to 2016, National Tables https://www.gov.uk/government/statistics/children-looked-after-in-englandincluding-adoption-2015-to-2016

Department for Education ( 2010). A review of the longitudinal study of young people in England https://www.gov.uk/government/publications/a-review-of-the-longitudinal-study-of-young-peoplein-england-Isype-recommendations-for-a-second-cohort

Elliott, J., \& Shepherd, P. (2006). Cohort profile of the 1970 British Birth Cohort (BCS70). International Journal of Epidemiology, 35, 836-843. doi:DOI: 10.1093/ije/dyl174 
Eurochild (2010). Children in Alternative Care: National Surveys, 2nd edition, Eurochild

Eurostat (2015). Being young in Europe today - family and society. Available from

http://ec.europa.eu/eurostat/statistics-explained/index.php/Being young in Europe today -

family and society

Frick, J. R. (2010). Introduction to the German Socio-Economic Panel (SOEP). Berlin

https://www.diw.de/documents/dokumentenarchiv/17/diw 01.c.353304.de/soep-

intro march2010.pdf

Geiger, J., \& Beltan, S. (2017). Experiences and outcomes of foster care alumni in postsecondary education: A review of the literature. Children and Youth Services Review, 79, 186-197

Gilbert, N., Parton, N. \& Skivenes, M. (Eds) (2011). Child Protection Systems: International Trends and Orientations, Oxford University Press

Gissler, M., \& Haukka, J. (2004). Finnish health and social welfare registers in epidemiological research. Norsk epidemiologi, 14(1), 113-120.

Hantrais, L. (2009). International Comparative Research: theory, methods and practice. London / New York: Palgrave. http://www.palgrave.com/research/hantrais/ July 2012

Harris Rome, S. \& Raskin, M. (2017). Transitioning Out of Foster Care: The First 12 Months. Youth \& Society, $0044118 \times 17694968$

Haydon, D. (2003). Teenage pregnancy and looked after children/ care leavers. Resource for teenage pregnancy co-ordinators. Iford:Barnardo's.

Heino, T., Hyry, S., Ikäheimo, S., Kuronen, M., \& Rajala, R. (2016). Reasons, backgrounds, services and costs concerning the placing of children outside the home. Main results from the HuosTa Project (20142015). National Institute for Health and Welfare (THL). Report 3/2016. 151 pages. Helsinki 2016.ISBN 978952-302-643-8 (printed); ISBN 978-952-302-644-5 (online publication)Hiles, D. , Moss, D. Wright, J.,\& Dallos, R. (2013). Young people's experience of social support during the process of leaving care: A review of the literature. Children and Youth Services Review, 35, 2059-2071

Hollingworth, K. \& Jackson, S. (2016). Falling off the Ladder: using focal theory to understand and improve the educational experiences of young people in transition from public care. Journal of Adolescence, 52, 146-153

Jackson, S. \& Sachdev, D. (2001). Better Education, Better Futures: Research, practice and the views of young people in public care. Ilford: Barnardo's 
Jackson, S. Cameron, C. (2014). Improving the Participation of Young People in Care in Further and Higher Education: European research and practice. London, Jessica Kingsley Publishers

Kestilä, L., Väisänen, A., Paananen, R., Heino, T., \& Gissler, M. (2012). Children placed in out-ofhome care as young adults. A register-based follow-up study on children born in 1987 in Finland Yhteiskuntapolitiikka, 77 (6),599-620.

Knight, A., Chase, E., \& Aggleton, P. (2006). 'Someone of Your Own to Love': Experiences of Being Looked After as Influences on Teenage Pregnancy. Children and Society, 20, 5, 391-403

Kääriälä, A., \& Hiilamo, H. (2017). Children in out-of-home care as young adults: A systematic review of outcomes in the Nordic countries. Children and Youth Services Review, 79, 107-114.

Kroh, M., Kühne, S., \& Siegers, R. (2015). Documentation of Sample Sizes and Panel Attrition in the German Socio Economic Panel (SOEP) (1984 until 2014). SOEP Survey Papers 297: Series C. Berlin: DIW Berlin / SOEP

Manninen, M. (2013). Koulukotiin sijoitettujen nuorten psykiatrinen oirekuva ja ennuste. Tutkimus: $2013 \_112$.

McGrath-Lone, L. (2018). Classifying longitudinal care histories for looked after children in England.Seminar presented at Thomas Coram Research Unit, UCL Institute of Education, 23 January Mc Grath-Lone, L., Dearden, L., Nasima, B., Harron, K. \& Gilbert, R. (2016). Changes in first entry to out-of-home care from 1992 to 2012 among children in England. Child Abuse \& Neglect, 51, 163-171 Mendes, P., Pinkerton, J. \& Munro, E. (2014). Young people transitioning from out-of-home care: an issue of social justice, Australian Social Work, 67(1), 1-4

Mezey, G., Robinson, F. Gillard, S., Mantovani, N. Meyer, D., White, S., \& Bonell, C., ( 2017). Tackling the problem of teenage pregnancy in looked-after children: a peer mentoring approach. Child and Family Social Work, 22, 1, 527-536

Mostafa, R. \& Wigging, R. D. (2014). Handling attrition and non-response in the 1970 British Cohort Study. CLS Working Paper 2014/2. London: Centre for Longitudinal Studies.

Munro, E., Lushey, C., National Care Advisory Service, Maskell-Graham, D and Ward, H. with Holmes, L. (2012). Evaluation of the Staying Put: 18 Plus Family Placement Programme: Final report. London, DfES RR191 
O'Brien, K., Pecora, P., Echohawk, L., Evans-Campbell, T., Palmanteer-Holder, N., \& White, C. R. (2010). Educational and employment achievements of American Indian/ Alaska Native alumni of foster care. Families in Society.The Journal of Contemporary Social Services, 91(2), 149-157.

Paananen, R., \& Gissler, M. (2011). Cohort profile: the 1987 Finnish birth cohort. International journal of epidemiology, 41(4), 941-945

Pecora, P., Kessler, R., O'Brien, K., Roller White, C., Williams, J., Hiripi, E., English, D., White, J. and Herrick, M. (2006). Educational and employment outcomes of adults formerly placed in foster care: Results from the Northwest Foster Care Alumni Study. Children and Youth Services Review, 28, 12, pp 1459-1481

Petrie, P., Boddy, J., Cameron, C., Wigfall, V. and Simon, A. (2006). Working with Children in Care: European Perspectives. Buckingham, Open University Press

Propp, J., Ortega, D., and NewHeart, F.. (2003) Independence or Interdependence: Rethinking the Transition From Ward of the Court to Adulthood. Families in Society: The Journal of Contemporary Social Services: 2003, Vol. 84, No. 2, pp. 259-266. https://doi.org/10.1606/1044-3894.102

Pryce, J., Napolitano, L., and Samuels, G. (2017). Transition to Adulthood of Former Foster Youth: Multilevel Challenges to the Help-Seeking Process, Emerging Adulthood 1-11

Okpych, N. J., Feng, H., Park, K., Torres-García, A., \& Courtney, M. (2018). Living Situations and Social Support in the Era of Extended Foster Care: A View from the US. Longitudinal and Life Course Studies, 9(1), 6-29

Ristikari, T., Törmäkangas, L., Lappi, A., Haapakorva, P., Kiilakoski, T., Merikukka, M., \& Gissler, M. (2016). Growing up in Finland- a 25 year follow-up of the 1987 Finnish birth cohort. (Suomi nuorten kasvuympäristönä-25 vuoden seuranta vuonna 1987 Suomessa syntyneistä nuorista aikuisista). Raportti: 2016, 009.

Quilgars, D., Johnsen, S. and Pleace, N. (2008). Youth homelessness in the UK: A decade of progress? Joseph Rowntree Foundation

Schoon, I., \& Bynner, J. (Eds.). (2017). Young People's Development and the Great Recession: Uncertain Transitions and Precarious Futures. Cambridge: Cambridge University Press

Sebba, J., Berridge, D., Luke, N., Fletcher, J., Bell, K., Strand, S., Thomas, S., Sinclair, I., O'Higgins, A. (2015). The Educational Progress of Looked After Children in England: Linking care and educational data. Available from http://reescentre.education.ox.ac.uk/wordpress/wpcontent/uploads/2015/11/EducationalProgressLookedAfterChildrenOverviewReport_Nov2015.pdf 
Settersten, R. A., \& Ray, B. (2010). What's Going on with Young People Today? The Long and Twisting Path to Adulthood. Future of Children, 20(1), 19-41

Singer, E. \& Berzin, S. (2015). Early Adult Identification Among Youth With Foster Care Experience: Implications for Emerging Adulthood, Journal of Public Child Welfare, 9, 65-87

Statistisches Bundesamt (2016). Kinder- und Jugendhilfestatistik. Berichtsjahr 2015. Wiesbaden: DESTATIS

Stein, M. (2006). Research review: young people leaving care. Child and Family Social Work, 11( 3), 273-279

Stein, M. \& Munro, E. (Eds) (2008). Young People's Transitions from Care to Adulthood: International Research and Practice, London, Jessica Kingsley.

Stein. M (2013). Young people's transitions from care to adulthood in European and postcommunist Eastern European and Central Asian societies, Australian Social Work. Available at: http://www.tandfonline.com/doi/full/10.1080/0312407X.2013.836236

UN General Assembly (2010). Guidelines for the Alternative Care of Children: resolution / adopted by the General Assembly, 24 February, A/RES/64/142, available from:

http://www.refworld.org/docid/4c3acd162.html [accessed 17 August 2017]

Wagner, G. G., Frick, J. R., \& Schupp, J. (2007). The German Socio-Economic Panel Study (SOEP) Scope, evolution and enhancements. Schmollers Jahrbuch, 127, 161-191.

http://dx.doi.org/10.2139/ssrn.1028709.

Walther, A. (2009). „It was not my choice, you know?“ Young people's subjective views and decision making processes in biographical transitions, in: Schoon, Ingrid/Silbereisen, Rainer K. (Eds.):

Transitions from School to Work: Globalisation, Individualisation, and Patterns of Diversity. Cambridge: Cambridge University Press, 121-145.

Walther, A., Warth, A., Ule, M., \& du Bois-Reymond, M. (2015). 'Me, my education and I': constellations of decision-making in young people's educational trajectories. International Journal of Qualitative Studies in Education, 28(3), 349-371. doi:10.1080/09518398.2014.987850

Youth Justice Board (2017). Monthly Youth Custody Report available from https://www.gov.uk/government/statistics/youth-custody-data 